\title{
Humble Practice in Engineering: What does it look like?
}

Ellen Lynch, Amy McLennan and Jeremy Smith • Australian National University, Canberra

WHY? To tackle modern challenges, engineers must be able to work within complex teams, environments and projects. Collaborating across disciplines and sectors requires honing and nurturing specific interpersonal skills and attributes. These include open-mindedness, collaboration communication, emotional intelligence, stakeholder management and empathy. All of these skills and attributes require high self-awareness and other-orientedness. In my research, this is encapsulated by the term "humble practice".

Unlike concepts such as empathy (Hess, Beever, Strobel, \& Brightman, 2017; Strobel, Hess, Pan, \& Wachter Morris, 2013), humble practices have not been investigated in engineering, despite these behaviours and actions being reflected in engineering competencies (Engineers Australia, 2012a, 2012b, 2018).

WHAT? Broadly, the requirements of engineers are driven by competency-based accreditation systems such as Engineers Australia (EA) and ABET. These highlight the need for engineers to build 'happy, healthy and prosperous communities' (Engineers Australia, 2017) and be socially and environmentally aware, considering global, economic, public health, safety and welfare (ABET, 2019; Birzer \& Hamilton, 2019; Engineers Australia, 2012b). This inherently requires awareness that one's knowledge and perspective are fallible, and respect for knowledge and perspective outside of your own, key aspects of humility.

\section{HOW?}

This study seeks to understand engineers' perspectives on humility and humble practice in Australian workplaces. The definition of humility is constructed from literature as an attitude to our personal and others limitations.

Interviews of 20 engineers in Australia will be used to understand experiences of building relationships in the workplace and how humble practice influences technical outcomes through relationships. To be representational of the profession in Australia, the participants will cover 13 major disciplines and sectors, have 10-20 years' experience, represent the $15 \%$ of females in the profession and $85 \%$ of males, and the high proportion of migrant engineers.

The interviews will never explicitly mention the term 'humility', instead seeking qualitative experiences of 4-5 key aspects of humility, reflected in a developing model.

YOUR INPUT

We invite your contribution and thoughts on this ongoing project.

Click HERE to tell me about a time you saw something resembling humble practice in the workplace or in your work, or complete the activity below.

"Personally, I see humility in admitting you don't know something. When someone seeks clarification on an item, casually admitting that they don't know what an acronym means, or why a certain material is better than another, that demonstrates humble practice. They are confident in their own knowledge and would like to increase their knowledge and understanding, without ego."

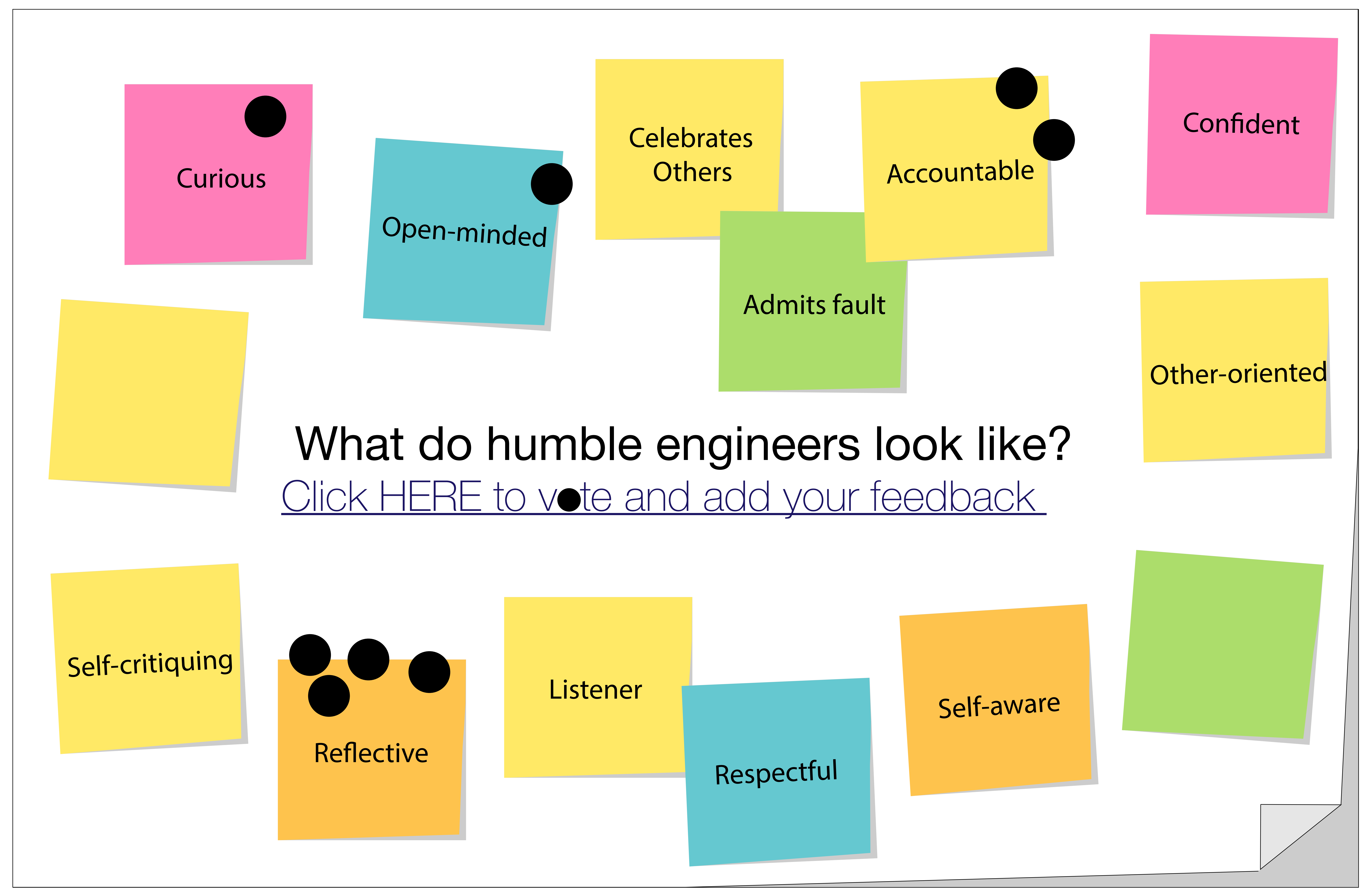

